Provided for non-commercial research and education use. Not for reproduction, distribution or commercial use.

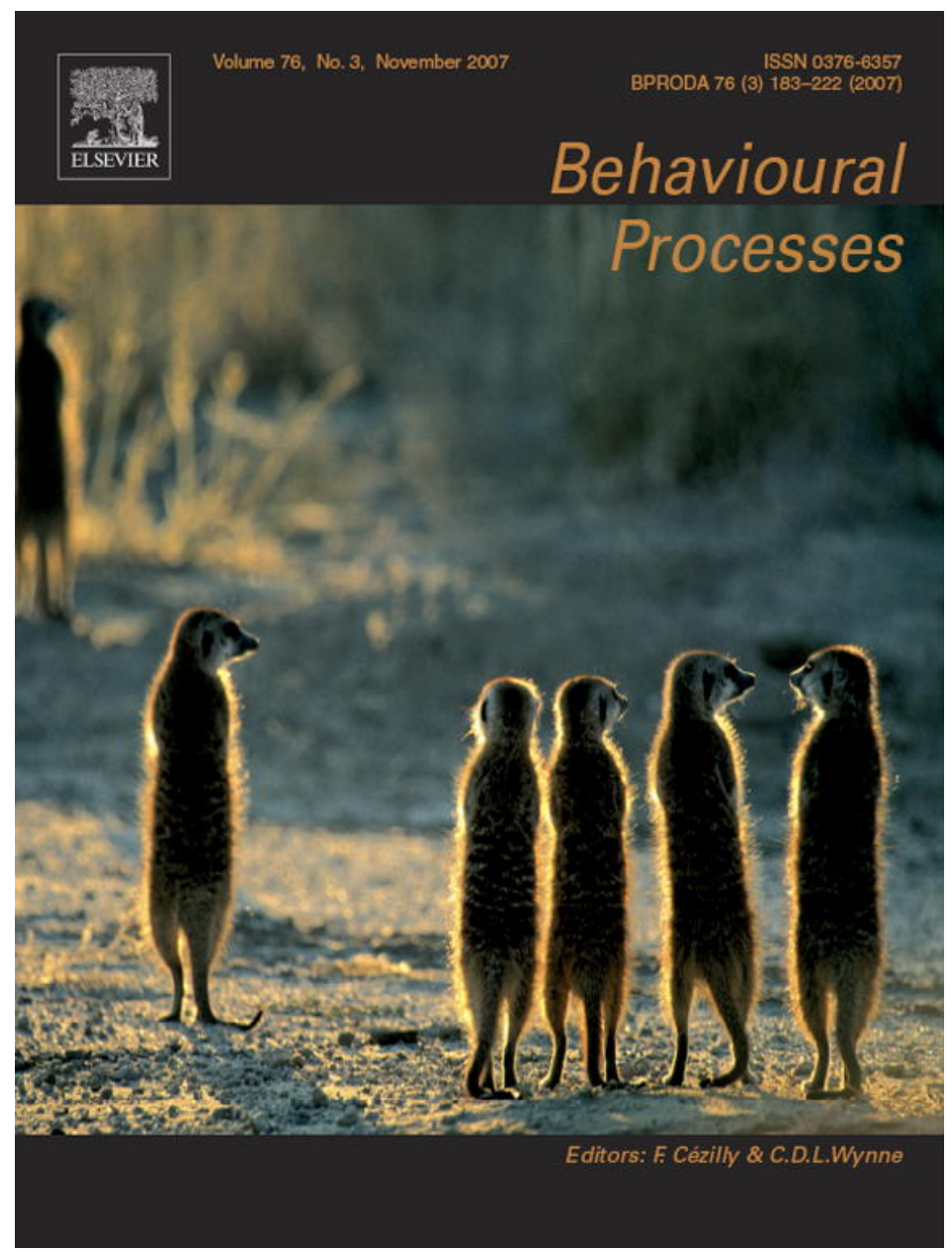

This article was published in an Elsevier journal. The attached copy

is furnished to the author for non-commercial research and education use, including for instruction at the author's institution, sharing with colleagues and providing to institution administration.

Other uses, including reproduction and distribution, or selling or licensing copies, or posting to personal, institutional or third party websites are prohibited.

In most cases authors are permitted to post their version of the article (e.g. in Word or Tex form) to their personal website or institutional repository. Authors requiring further information regarding Elsevier's archiving and manuscript policies are encouraged to visit: 


\author{
Rapid report
}

\title{
Flexible expression of a food-processing behaviour: Determinants of dunking rates in wild Carib grackles of Barbados
}

\author{
Julie Morand-Ferron*, Louis Lefebvre \\ Department of Biology, McGill University, 1205 Docteur Penfield, Montréal, Québec, Canada H3A 1B1 \\ Received 5 January 2007; received in revised form 13 May 2007; accepted 15 May 2007
}

\begin{abstract}
Dunking, the softening of dry food in water to speed up consumption time, is normally a very rare behaviour in wild Carib grackles (Quiscalus lugubris) of Barbados. Its frequency can be experimentally increased when large numbers of dry items are repeatedly placed near a standing source of water in conditions that minimize intraspecific competition and risk of theft. To reconcile the normally low frequency of the behaviour in the wild with the high rates obtained in previous experiments, we tested three conditions where dunking varied between 0 and $70 \%$. Dunking was very rare when it had been made unnecessary by pre-soaking the food, water was far from the dry items offered and only one food item was given, focusing all competitive interactions and theft attempts on a single individual. In contrast, dunking rate was high when food was not pre-soaked, water was close to dry food and more than one item (and hence target for competition and theft) was given. These experiments confirm that dunking rates, like other proto-tool-like food-processing techniques, depend on the costs and benefits of the situation where they are used. (C) 2007 Elsevier B.V. All rights reserved.
\end{abstract}

Keywords: Behavioural flexiblity; Dunking behaviour; Food-processing; Quiscalus lugubris; Tool-use

Behaviours in which food is softened in water, battered on a hard surface or dropped on a rock allow animals to gain access to items that would otherwise be difficult or impossible to consume. Along with the use of bait, skewers and wedges, these food-processing techniques are traditionally included under the blanket category of proto-tool behaviours, in which animals use external implements that are not detached from their substrate and, therefore, not directly manipulated (Parker and Gibson, 1977; Beck, 1980; Lefebvre et al., 2002). Beyond their benefits, these techniques might expose animals to increased costs, such as longer handling times or increased risk of food theft. Whether a food-processing technique or another foraging behaviour are used in a given context should depend on the balance of costs and benefits of the alternatives. For example, green herons use bait to attract fish when their normal wait-and-strike technique is less efficient due to water depth and foliage cover (Higuchi, 1988). Tebbich et al. $(2001,2002)$ have shown that, while woodpecker finches from both dry and humid habitats could learn to use twigs

\footnotetext{
* Corresponding author at: Département des Sciences Biologiques, Université du Québec à Montréal, C.P. 8888 Succursale Centre-Ville, Montréal, Québec, Canada H3C 3P8. Tel.: +1 514 9874118; fax: +1 5149874647.

E-mail address: morand-ferron.julie@uqam.ca (J. Morand-Ferron).
}

to pry arthropods out of tree crevices, the rate of twig-tool-use is much higher in dry habitats, where foliage gleaning is relatively inefficient. There is thus increased recognition that the rates of food-processing and tool-related behaviours can be ecologically determined (e.g. de Moura and Lee, 2004) and that understanding the variables that act on their costs and benefits is a key to explain variation in rates of expression of these techniques in the wild.

In this paper, we examine three factors that cause dunking in wild Carib grackles (Quiscalus lugubris) of Barbados to vary between very high and very low rates. Carib grackles are groupfeeding icterids that rely heavily on anthropogenic food sources in urban areas of Barbados (Jaramillo and Burke, 1999). When faced with dry food, Carib grackles occasionally bring the item to a standing source of water and drop or dip it once or repeatedly for several seconds, subsequently eating the softened item on the spot or flying off to consume it on a tree (see Hickey, 2005 for a photograph). Theft is a major cost of dunking, as approximately $10-15 \%$ of items are stolen by intraspecific competitors. Despite the fact that dunking has been reported in five species of Quiscalus (and over 30 species of birds in the wild; see Table 1 in Morand-Ferron et al., 2004), it can be extremely rare in $Q$. lugubris and had never been noticed before 2001 in 15 years of field research by our group. In previous studies (Morand-Ferron 
et al., 2004, 2006), normally the very low frequency of dunking in the wild has been experimentally increased up to $50 \%$ by repeatedly providing, at the same site, large numbers of dry food items very close to water. Here, we examine situations that more closely resemble the ones grackles normally encounter in the wild, namely a low number of food items and a greater distance between food and water. We also intersperse trials where dunking is unnecessary (items are pre-soaked) amidst experimental conditions that elicit high dunking rates, to examine the flexibility of the behaviour and eliminate the possibility that repeated elicitation and reward of dunking at a predictable site may have led to a simple conditioned response to visual contiguity between food and water. We predict near zero rates of dunking when food is pre-soaked or far from water or so rare that all competitive interactions and theft attempts are focussed on a single individual. To make sure that the predicted low rates are due to the costs and benefits of our experimental situations, we compare them with conditions where dunking rates are expected to be much higher, respectively, hard un-soaked food, water in the immediate vicinity of hard dry food and multiple items yielding multiple simultaneous targets for competitors and eventual thieves.

All experiments, totaling 1980 food items presented over 396 trials, were conducted at the Bellairs Research Institute of McGill University, St. James, Barbados. Grackles, there are used to drink from water puddles that accumulate after rain showers on the roofs or terraces of buildings; these puddles can be maintained at regular water levels via refilling and lining with plastic sheets. Experiment 1 was conducted on the roof of the Brace apartment, while experiments 2 and 3 were conducted on the terrace of Seabourne flat, situated $0.2 \mathrm{~km}$ from Brace.

In experiment 1 , we first conducted five preliminary trials in which we provided 50 dry dog pellets (a food type readily eaten by grackles; Dolman et al., 1996) $2 \mathrm{~m}$ from a circa $1.5 \mathrm{~m}^{2}$ puddle to habituate the birds to feed on the site. Grackles were then given a series of 30 trials in which 10 dry dog pellets were randomly placed either $5,4,3,2,1$ or $0.1 \mathrm{~m}$ from a puddle $(60 \mathrm{~cm}$ diameter). The observer, situated $12 \mathrm{~m}$ from the puddle, noted the number of pellets taken and dunked by Carib grackles on each trial. In Barbados, observations from a distance of $5 \mathrm{~m}$ or more do not affect $Q$. lugubris, which (like Zenaida aurita and Loxigilla noctis) are extremely tame on this island (Lefebvre, 1996).

In experiment 2 , two preliminary trials were conducted in which the birds were first habituated to feed on the site by being given 100 dog pellets $2 \mathrm{~m}$ from a circa $1.5 \mathrm{~m}^{2}$ water puddle. After this phase, the birds were presented with either one or three dry dog pellets 10 times in a row. We chose three pellets as the control for the single item trials to attract approximately the same number of competitors to the site; experiments where larger numbers are given can attract over 30 grackles at a time (Morand-Ferron et al., 2004). We alternated between one and three pellets series, for a total of 48 trials (each composed of 10 series of one or three pellets) over 4 days. The observer again noted the number of pellets Carib grackles took and dunked per trial.

In experiment 3 , birds were habituated to feed on the site by conducting four preliminary trials in which we provided 100 dry dog pellets $2 \mathrm{~m}$ from the water puddle. After this phase, a series of 66 randomly determined trials was conducted in which 10 dog pellets, either dry or pre-soaked for $10 \mathrm{~s}$, were presented $2 \mathrm{~m}$ from the puddle. For each trial in this phase, the number of pellets taken and dunked by Carib grackles was noted by a single observer sitting $7 \mathrm{~m}$ from the puddle. If dunking is a flexible response to food condition, then we should observe no dunking with pre-soaked items; if repeated elicitation and reward of dunking at the same site has led to a conditioned response to the visual cue of pellets near a puddle, then dunking rate should be high whether the items are pre-soaked or not.

Trials are the appropriate statistical unit for experiments of the type conducted here, as multiple dunking by the same individual over the course of days is possible, excluding independent measures, but too sporadic for a repeated measures design to be feasible. To verify this, we ran a series of 12 five-trial sessions in the situation likely to elicit the most dunking (10 dry pellets $0.1 \mathrm{~m}$ from water) and noted the identity of all dunking grackles that had individual leg bands fitted to them in the context of another study (Overington, unpublished). The 30 banded birds that dunked in these trials did so on an average of 2.8 items each (range 1-13, median 1) out of the 600 offered. When dunking occurred in a given session, the probability of it being done again by the same-banded bird within the same session was 0.17 . However, the probability of multiple dunking by the same individual in the same trial was negligible; we saw it only twice, both times after the initially dunked pellet was stolen by a conspecific. This is partly due to the fact that the 10-pellet trials lasted only an average of $255 \mathrm{~s}$, which is approximately the time a single nondunked item requires to be eaten (Morand-Ferron et al., 2006). We, therefore, analyzed our data with generalized linear models, using a binomial error and logit link (PROC GENMOD in SAS version 8.2 ; Kuss, 2002), with the proportion of items that were dunked in each trial as the response variable.

In all three experiments, grackles showed a large range of variation in dunking rate. On some trials, dunking rate was as high as $70 \%$ when 10 dry pellets were placed $0.1 \mathrm{~m}$ from the puddle. It fell to zero on trials where items were $5 \mathrm{~m}$ from the puddle or pre-soaked or when as many as 25 grackles converged on the single pellet offered. Dunking rate was negatively correlated with the distance between the water source and the food presented $\left(\chi_{1}^{2}=9.6 ; n=30, P=0.002\right.$; Fig. 1$)$. The proportion of food items dunked per trial was higher when birds were presented with three versus one item(s) per trial $(33.2 \%$ versus $17.8 \%$, respectively; $\chi_{1}^{2}=9.2 ; n=48, P=0.002$; Fig. $2 \mathrm{a}$ ). Rates of dunking were also much higher with dry than with pre-soaked items (31.1\% versus $3.8 \%$, respectively; $\chi_{1}^{2}=48.3$; $n=66, P<0.001$; Fig. 2b).

Experiments that provide items that are difficult to ingest, reduce intraspecific competition and increase the spatial contiguity between water and dry food produce the highest dunking rates. These high rates are typical of what Morand-Ferron et al. (2004) obtained on caged individuals, who faced no competitors and were provided with hard and dry food pellets $30 \mathrm{~cm}$ from a bowl of water. In a tropical island such as Barbados, water sources can be rare, especially in the dry season, and Carib grackles may often face high travel costs when dunking. More- 


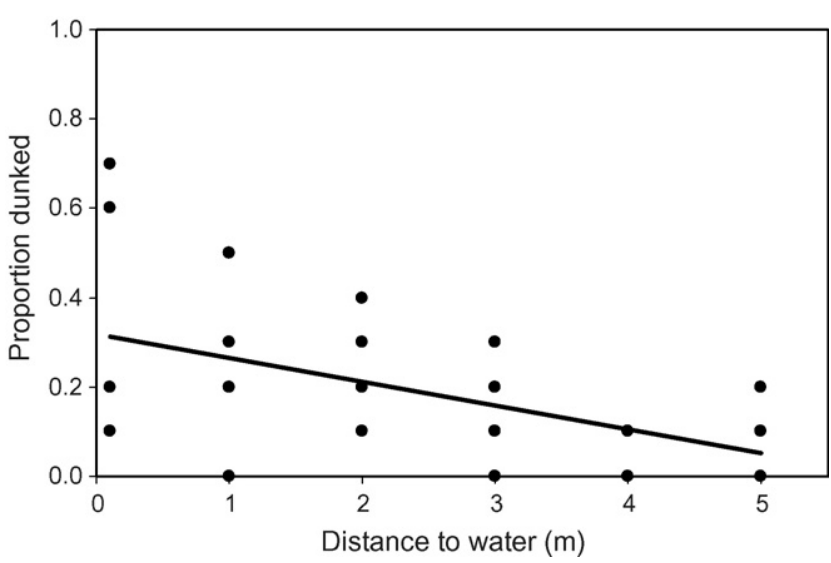

Fig. 1. Mean dunking rates (number of items dunked over the number taken by Carib grackles) as a function of distance between the water source and the food pile.

over, intraspecific competition for food is intense in $Q$. lugubris, with frequent agonistic displays and food theft (Morand-Ferron et al., 2006). These factors might contribute to explain the low frequency of this food-processing behaviour in normal field conditions in Carib grackles of Barbados. Nut-cracking rates in wild capuchin monkeys (Cebus libidinosus) in Piauí, Brazil, also seem to be ecologically determined, with abundant anvil sites and palm nuts produced at ground level but inaccessible to direct consumption being suggested as an explanation for high rates of tool-use there (Fragaszy et al., 2004).
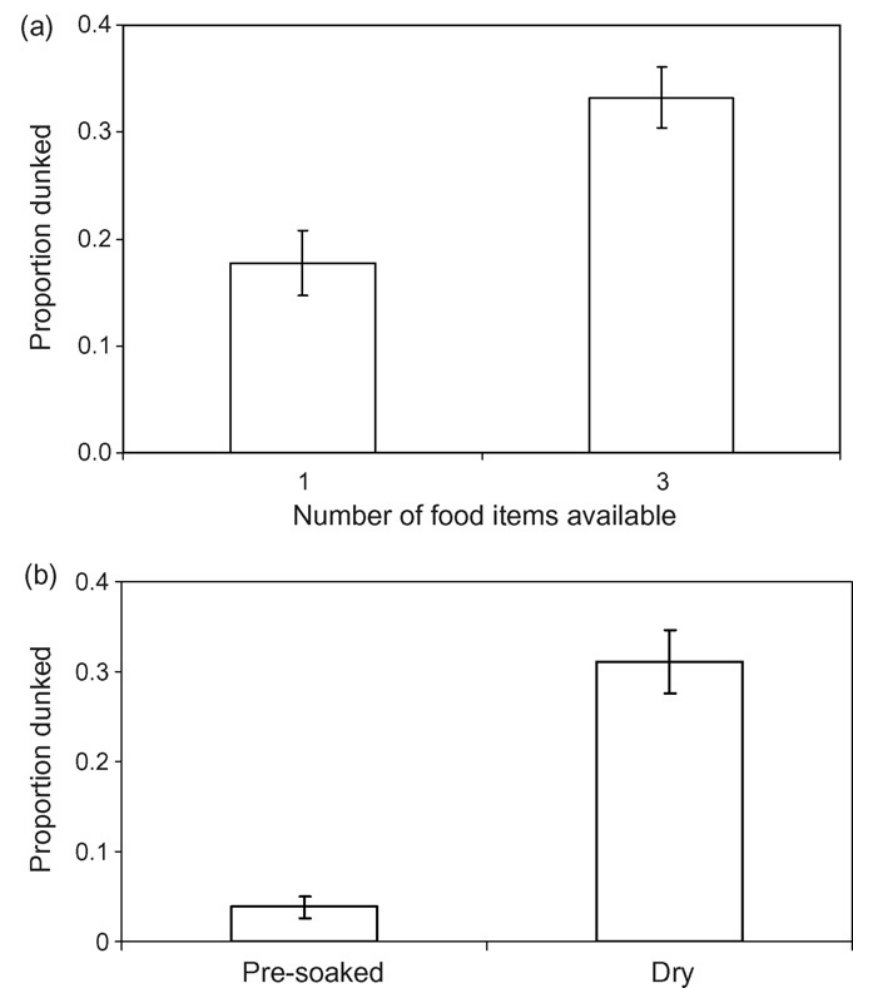

Fig. 2. Mean dunking rates (number of items dunked over the number taken by Carib grackles) with (a) one versus three item(s), and (b) pre-soaked versus dry items.
The linear decrease in dunking rate with distance can be functionally interpreted as a response to increased travel cost or mechanistically as a response to changed spatial contiguity in the two sets of stimuli that elicit dunking behaviour. The two interpretations cannot be distinguished by our experiments and are in any case not mutually exclusive, corresponding to different levels of explanation. It is interesting to note, however, that one behaviour often seen with pre-soaked pellets, walking towards the puddle but stopping short of dunking, was not seen at large distances between the water and the food source. At 4-5 m, grackles would simply fly off with a pellet in their beak without walking towards the puddle even for a short distance. From these anecdotal observations, one can speculate that, in experiment 1 , the decision to dunk or not was taken when the item was seized, but in experiment 3 , it was taken a few seconds later, after the bird has had time to assess the condition of the pellet by pressing it in its beak. Such an interpretation is consistent with the finding by Morand-Ferron et al. (2006) that kleptoparasites indiscriminately target birds with dunked and un-dunked pellets because they cannot visually distinguish the status of the food. Our results here suggest that the distinction is instead tactile or gustatory, dependent on in any case of having the food in the beak. The fact that dunking still occurred, albeit with a low frequency, with pre-soaked items may mean that our softening treatment was not sufficient or that some birds occasionally dunk without correctly assessing the condition of the food; it is impossible to distinguish between these possibilities at this stage. Overall, our experiments confirm that dunking is a flexible behaviour that depends on the state of the food and the spatial contingencies involving food and water. These results complement previous studies (Morand-Ferron et al., 2004, 2006) conducted in conditions that were less similar to those normally faced by Carib grackles of Barbados. Future work should now focus on individual differences in costs and benefits associated with dunking behaviour and alternative foraging tactics.

\section{Acknowledgments}

Funding for this work was provided by an NSERC grant to L.L. and an FQRNT postgraduate scholarship to J.M.F. This study was conducted under McGill Animal Use Protocol number 4887.

\section{References}

Beck, B.B., 1980. Animal Tool Behavior: The Use and Manufacture of Tools by Animals. Garland, New York.

de Moura, A.C., Lee, P.C., 2004. Capuchin stone tool use in Catinga dry forest. Science 306, 1909.

Dolman, C.S., Templeton, J., Lefebvre, L., 1996. Mode of foraging competition is related to tutor preference in Zenaida aurita. J. Comp. Psychol. 110, 45-54.

Fragaszy, D., Izar, P., Visalberghi, E., Ottoni, E.B., De Oliveira, M.G., 2004 Wild capuchin monkeys (Cebus libidinosus) use anvils and stone pounding tools. Am. J. Primatol. 64, 359-366.

Hickey, G., 2005. Dunking birds. Nature Australia, Winter: 16.

Higuchi, H., 1988. Individual differences in bait-fishing by the green-backed heron Ardea striata associated with territory quality. Ibis 130, 39-44.

Jaramillo, A., Burke, P., 1999. New World Blackbirds: the Icterids. Princeton University Press, Princeton 
Kuss, O., 2002. How to use SAS for logistic regression with correlated data. In: Proceedings of the annual SAS Users Group International Conference, vol. 27, pp. 1-5.

Lefebvre, L., 1996. Raging Dove. Nat. Hist. 105, 34-37.

Lefebvre, L., Nicolakakis, N., Boire, D., 2002. Tools and brains in birds. Behaviour 139, 939-973.

Morand-Ferron, J., Lefebvre, L., Reader, S.M., Sol, D., Elvin, S., 2004. Dunking behaviour in Carib grackles. Anim. Behav. 68, 1267-1274.

Morand-Ferron, J., Veillette, M., Lefebvre, L., 2006. Stealing of dunked food in Carib grackles (Quiscalus lugubris). Behav. Processes 73, 342-347.
Parker, S.T., Gibson, K.R., 1977. Object manipulation, tool use and sensorimotor intelligence as feeding adaptations in Cebus monkeys and great apes. J. Hum. Evol. 6, 623-641.

Tebbich, S., Taborsky, M., Fessl, B., Blomqvist, D., 2001. Do woodpecker finches acquire tool-use by social learning? In: Proceedings of the Royal Society of London Series B-Biological Sciences, vol. 268, pp. 21892193.

Tebbich, S., Taborsky, M., Fessl, B., Dvorak, M., 2002. The ecology of tool-use in the woodpecker finch (Cactospiza pallida). Ecol. Lett. 5, $656-664$. 